\title{
Design of Dual Band Circular Polarization Stacked Microstrip Antenna for GPS Applications
}

\author{
Dr. Yessar E. Mohammed Ali \\ Dept. Electrical Engineering \\ College of Engineering/University of Mosul /Iraq 2013 \\ a.yessar@yahoo.com \\ ah_8611@yahoo.com
}

\begin{abstract}
In this paper dual-band microstrip antenna for Global Positioning System (GPS) application is designed. This design contents on two circular patch ( upper circular patch, lower circular patch) printed on a two-layer substrate of an FR4 dielectric layer, and cutting a crossed-slot in the upper patch and four I slots in the lower patch. The antenna can work at GPS LI band $(1.575 \mathrm{GHz})$ and L2 band $(1.227 \mathrm{GHz})$. The design achieved an approximately impedance bandwidth of $15.8 \mathrm{MHz}$ for $\mathrm{L1}$ for two ports, while $\mathrm{L} 2$ band is $11.8 \mathrm{MHz}$ for two ports with maximum gain of $2.54 \mathrm{dBi}$ and $1.177 \mathrm{dBi}$ in the $\mathrm{L} 1$ and $\mathrm{L} 2$ band respectively for two ports . The resulting circular polarization (with axial ratio $\leq 3 \mathrm{~dB}$ ) has been found to meet that required for this application. The VSWR is approximately 1.1 (VSWR $\leq 2)$ for $L 1$ and 1.2 for L2. Results were obtained above using the software CST, which shows that this antenna can meet the demands of the signals of satellite navigation system. The antenna dimensions are $\left(70 * 70 \mathrm{~mm}^{2}\right)$. The structure is compact and has a good application prospect. The results with lowprofile characteristics make the antenna suitable for GPS applications.
\end{abstract}

Keywords: microstrip antenna, GPS antenna, Circular polarization, dual-band antenna, Global Positioning System.

$$
\text { تصميم هوائي شريحة رقيقة متكلس ثنائي الحزمة ذو استقطاب دائري لاستخدامه في المواقع }
$$

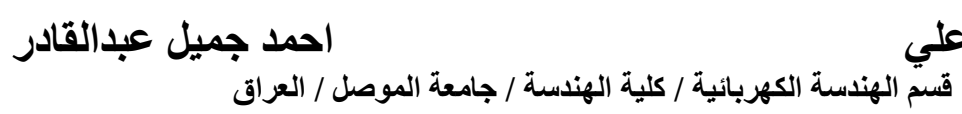

\section{الخلاصة}

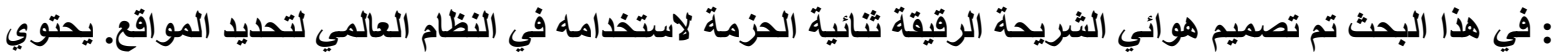

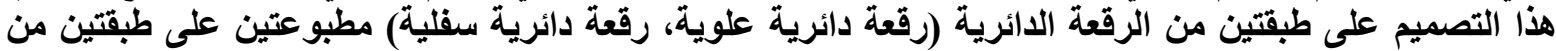

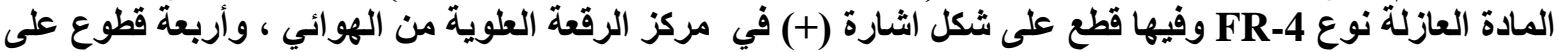

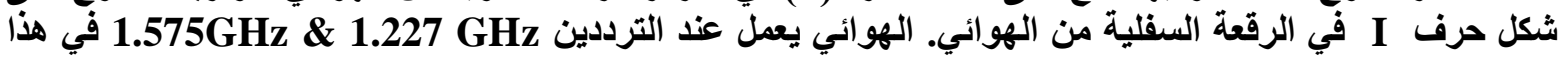

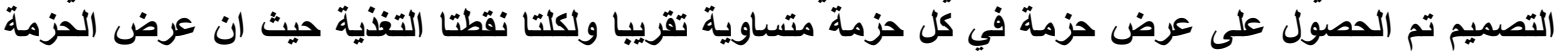
للحزمة الاولى هي

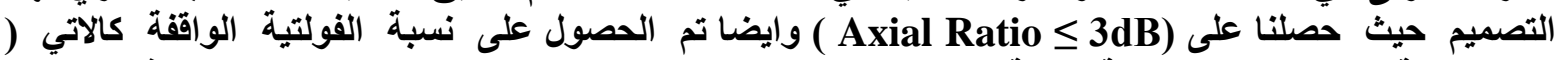

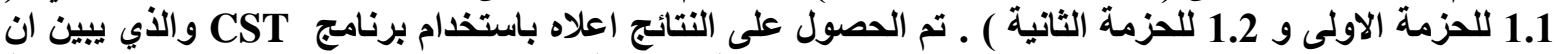

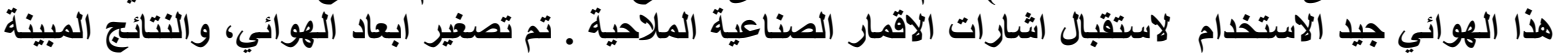

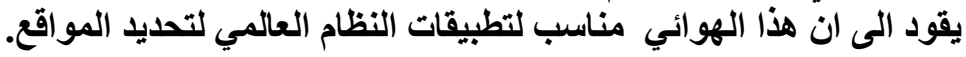




\section{1- Introduction}

Because of their low-profile advantage, circularly polarized (CP) microstrip antennas are very attractive for global positioning system (GPS) applications. However, many of the related designs available in the open literature, operate at the GPS band at $1575 \mathrm{MHz}$ only. Some designs can cover the two GPS bands at 1227 and $1575 \mathrm{MHz}$, which is necessary in more demanding operations, such as those requiring differential GPS operation [1]. Recently, in order to satisfy the demand for precise and reliable GPS receivers, a highperformance CP antenna covering both L1 and L2 bands is required. Dual-band stacked microstrip antennas, such as antenna structures with an air layer [2] or two different dielectric substrate layers [3], have also been reported for GPS. Both the air layer and the two dielectric substrate layers enable the antennas to carry out the dual-band CP operation, thereby achieving good impedance matching at the two CP operating frequencies. However, the stacked antenna leads to an increase in fabrication complexity. The $\mathrm{CP}$ antenna can be used to reduce the multipath effect around a GPS receiver [4].The CP antennas are classified as a single feed type or dual feeds type depending on the number of feed point necessary to generate the $\mathrm{CP}$ waves. The dual feeds method has a complex result in larger geometry [5]. Thus, a single feed CP structure, which has a small occupied volume; less complexity, is desired in situation, where it is difficult to place the dual orthogonal feed. In addition, the single feed also does not require an external polarizer [6]. Antennas fed by two probes on the microstrip antenna feed rate equal to $90^{\circ}$ phase difference of the two signals, the two feed points, can be formed at right angles to the distribution of circular polarization of radiation. In this paper a dual band $\mathrm{CP}$ stacked microstrip antenna is presented using availably common dielectric laminates, which operates at both L1 and L2 frequency bands for GPS applications. Two circular patches are used for obtaining CP characteristics in the dual-band. The antenna is designed and optimized by CST.

\section{2- Theory :}

Patch style GPS antennas are very popular due to their small size and low profile. Low cost low profile single frequency, single-feed GPS patch antenna designs are commonly used in cell phone or vehicle applications where size and cost are key considerations. There are also low cost patch designs using dual orthogonal feeds .In our study we are going to build a microstrip antenna that it's going to work with circular polarization, this kind of antennas is widely used as efficient radiators in satellite communications because of the advantages that can provide. The most important of these advantages is that the orientation of the transmitting antenna and receiving antenna orientation need not necessarily be the same, so this allows the designer to have more freedom to design the transmission and reception system. With the use of circular polarized antennas, the system can tolerate changes in the polarization of the signal, these changes may be caused by the reflectivity, absorption, multipath, inclement weather and line of sight problems; conditions that (most of the time) can affect the polarization of a transmitted wave. Hence, circular polarized antennas give us a higher probability of a successful link because they can transmit and receive signals on all planes [7]. In an antenna, circular polarization can be achieved through a single feed or using two feeds in the same patch. In an antenna array, we can generate circular polarization by the sequential rotation of the feeders. The most common and direct way to generate a circular polarization is through the use of a dual-feed technique. The two orthogonal modes required for the generation of circular polarization can be simultaneously 
excited using two feeds at orthogonal positions that are fed by $1\left\llcorner 0^{\circ}\right.$ and $1\left\llcorner 90^{\circ}\right.$ as shown in Figure 1.

During the design of GPS microstrip antenna, the axial ratio of antenna is a vital parameter Usually a pure circular polarization (CP) antenna cannot be made in practice, and the axial ratio (AR) is used to describe the polarization performance of a $\mathrm{CP}$ antenna. It is defined as the ratio of the major axis to the minor axis of the elliptic polarization. It is a ratio of electric field amplitudes (not powers), usually expressed in $\mathrm{dB}$ that is [8]:

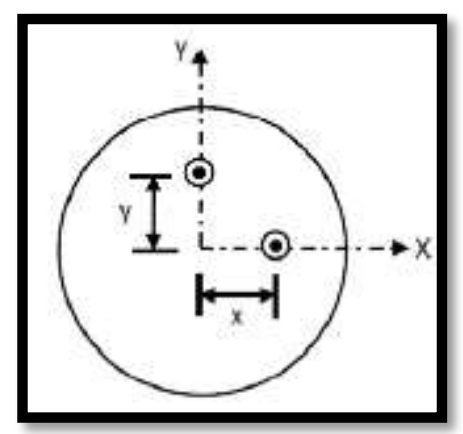

Figure (1) : Dual feed in a circular microstrip antenna.

$A R(d B)=20 \log \left(\left|\vec{E}_{\text {max }}\right|\right)-20 \log \left(\left|\vec{E}_{\text {min }}\right|\right)$

If the axial ratio is $0 \mathrm{~dB}$, the antenna is pure circular polarization; if it is infinity, the antenna is linear polarization; If the axial ratio is somewhere in between, the polarization is elliptical. As the microstrip GPS antenna pick up the circular polarization signal efficiently, the axial ratio should be less than $3 \mathrm{~dB}$ in practice.

\section{3- Antenna Structure and Design}

The geometry of the proposed dual-band GPS antenna is shown in Figure 2. The antenna consists of crossed-slot in the upper patch and four I slots in the lower patch without an airgap layer resonating at the L1 and L2. The structure incorporate a round shape ground plane, two substrate layers and two radiating elements and two vertical probe connected to the patch. The upper patch with dimension of $0.1388 \lambda_{\mathrm{o}}$ and Lower patch with dimension of $0.135 \lambda_{\mathrm{o}}$ (where $\lambda_{\mathrm{o}}$ corresponding to center frequency). The antenna comprises two radiating patch which both is fabricated on FR-4 substrate with relative permittivity $\varepsilon_{\mathrm{r}}=4.3$, tangent loss $\delta=0.025$ and thickness $h_{u}=0.8 \mathrm{~mm}$, radius $26.375 \mathrm{~mm}$ for upper substrate and $h_{l}$ $=1.6 \mathrm{~mm}, 70^{*} 70 \mathrm{~mm}^{2}$ for lower substrate with two hole radius of $2 \mathrm{~mm}$.Fed from the center of $9.2 \mathrm{~mm}$, the dual-fed with $50 \mathrm{ohm}$ coax. The upper element is responsible for L1 band and the low element for L2 band.

Probe feed directly through the lower microstrip patch antenna through-hole to connect to the upper microstrip patch antenna. The relationship between the resonant frequency and the radius of the circular patch can be presented by the equation (2) [9].

$f_{m n} \frac{15 x_{m n}}{2 \pi a \sqrt{\varepsilon_{r}}}$

Among them, $x_{m n}$ is the m-zero of $\mathrm{J}_{\mathrm{n}}(\mathrm{x})$, obtained by look-up table; (a) is included in the equivalent radius of the edge effects, $\varepsilon_{r}$ is microstrip antenna medium plate relative dielectric constant [10]. 

No. 3

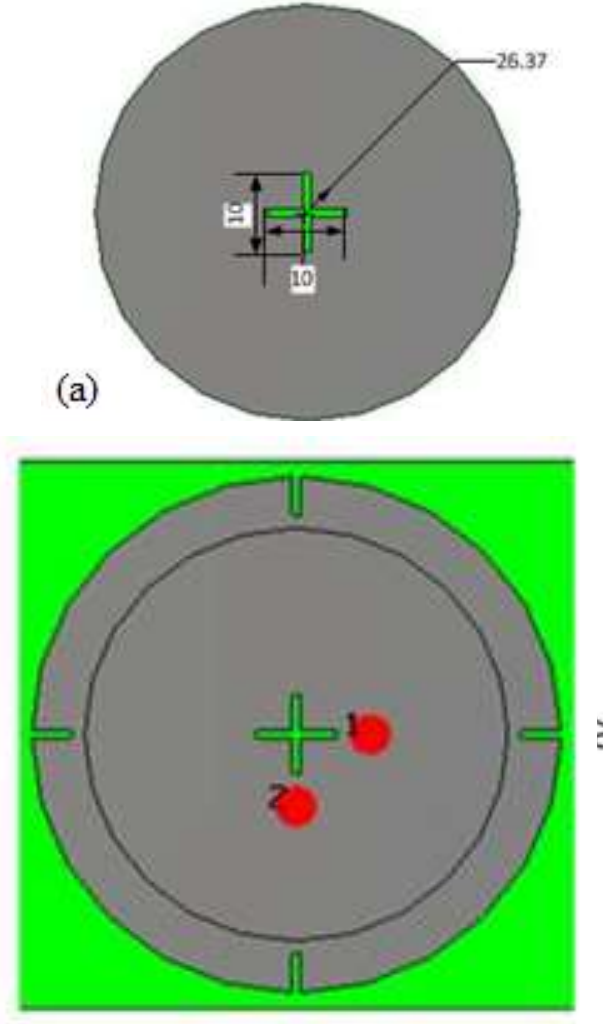

(c)

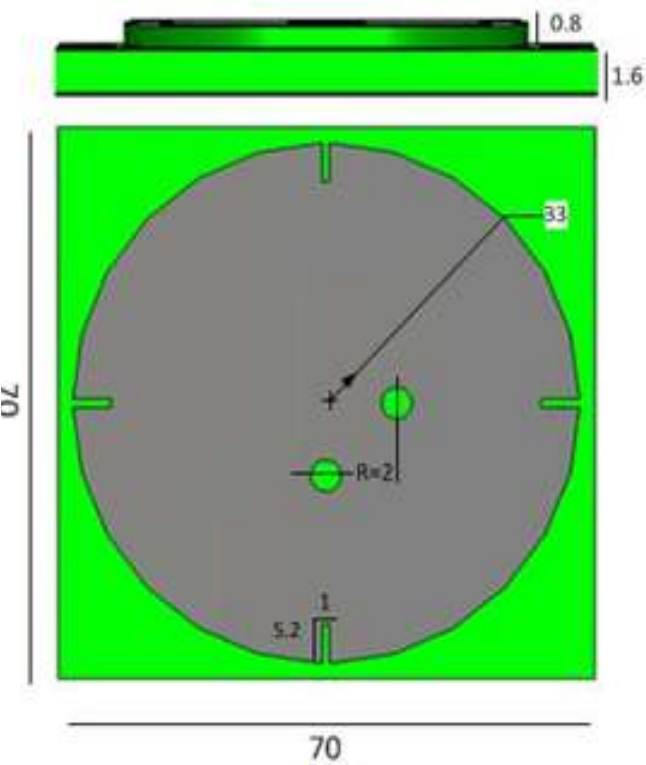

(b)

All dimensions in $\mathrm{mm}$

Figure (2) :The proposed antenna structure.

(a): Upper patch. (b): Lower patch.

(c): Final structure for proposed antenna

\section{4- RESULTS AND DISCUSSION :}

The characteristics of the proposed CP antenna are simulated by software CST version 2010. The simulated return loss is shown in Fig.3. Plot shows resonant frequencies at 1.575 $\mathrm{GHz}$ with minimum $-27.865 \mathrm{~dB}$ return loss and $1.227 \mathrm{GHz}$ with $-49.302 \mathrm{~dB}$ return loss for feed one and at $1.575 \mathrm{GHz}$ with minimum-26.894 dB return loss and $1.227 \mathrm{GHz}$ with $33.404 \mathrm{~dB}$ return loss for feed two.

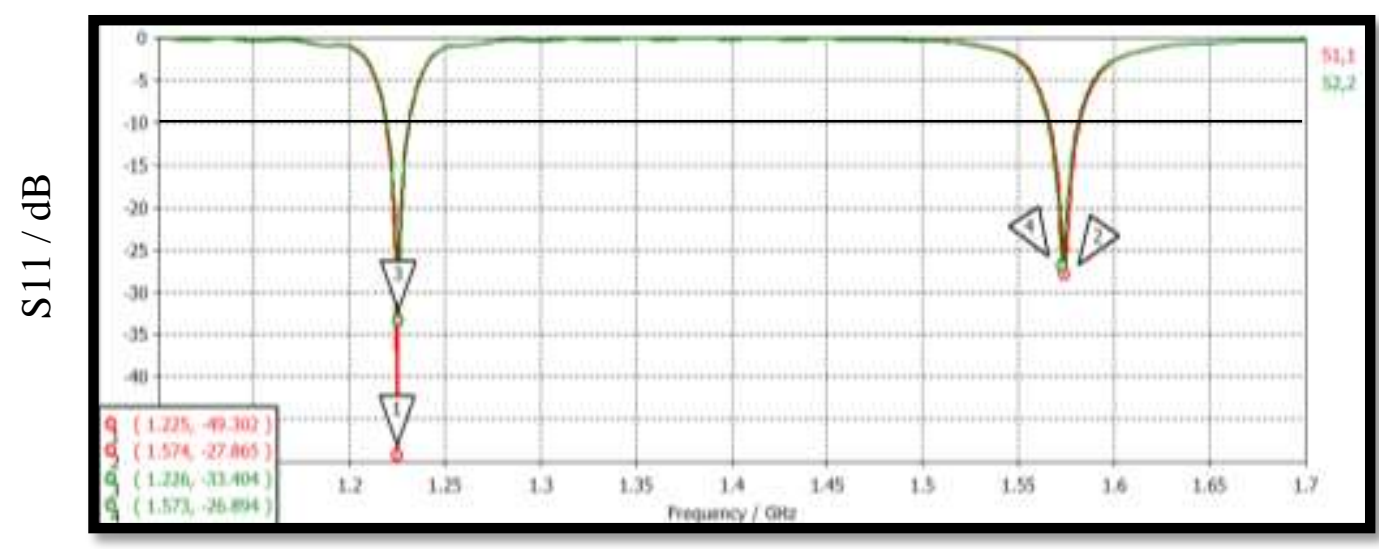

Figure (3) : The Return Loss of the proposed antenna. 
The simulated impedance bandwidths (-10dB return loss) for feed one are $11.8 \mathrm{MHz}$ from $1.2192 \mathrm{GHz}$ to $1.231 \mathrm{GHz}$ for lower band, while upper band covers $15.8 \mathrm{MHz}$ from 1.5667 $\mathrm{GHz}$ to $1.5825 \mathrm{GHz}$, The simulated impedance bandwidths (-10dB return loss) for feed two are $11.8 \mathrm{MHz}$ from $1.2198 \mathrm{GHz}$ to $1.2316 \mathrm{GHz}$ for lower band while upper band covers 15.7 MHz from 1.5656 GHz to $1.5813 \mathrm{GHz}$. Figure (4) represents the impedance (Real \& Imag. ) for the proposed antenna.

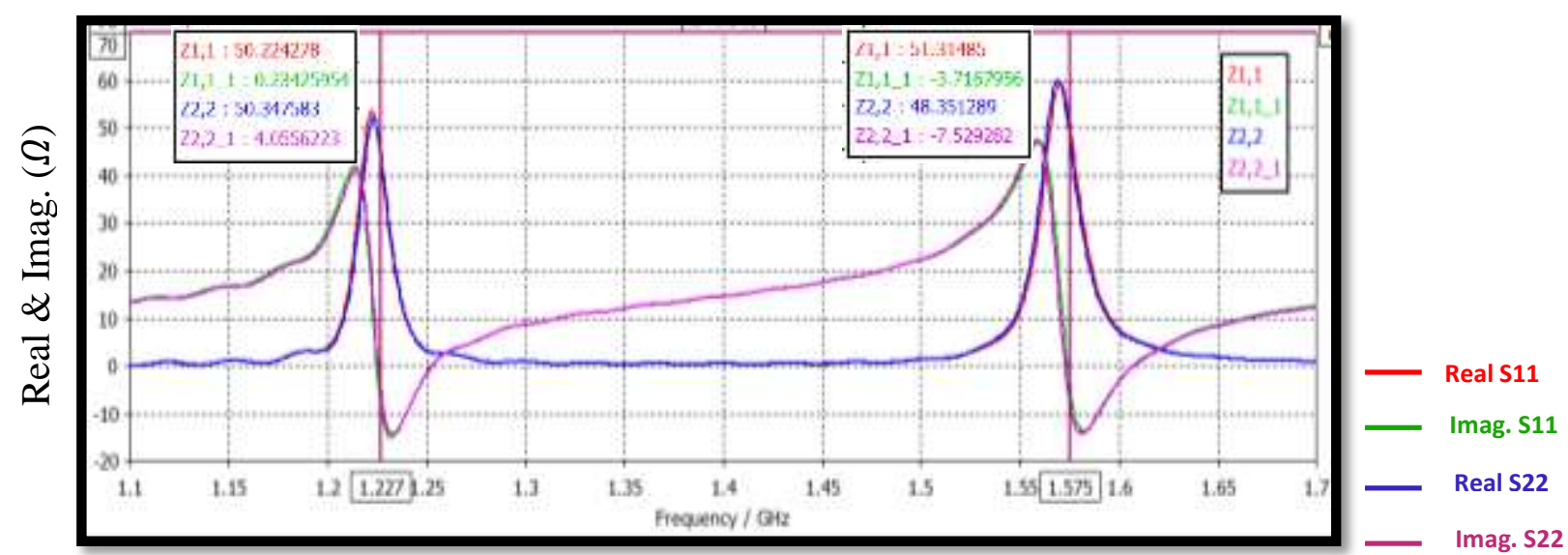

Figure (4) : The impedance of the proposed antenna.

Figure 5 illustrates the maximum antenna gain for frequencies across both of the operating bands. For the feed one, the antenna exhibits gain of $1.155 \mathrm{dBi}$ for the lower frequency band (L2) and a peak gain of $2.544 \mathrm{dBi}$ for the upper frequency band (L1), while for the feed two, the antenna exhibits gain of $1.177 \mathrm{dBi}$ for the lower frequency band (L2) and a peak gain of $2.549 \mathrm{dBi}$ for the upper frequency band (L1).

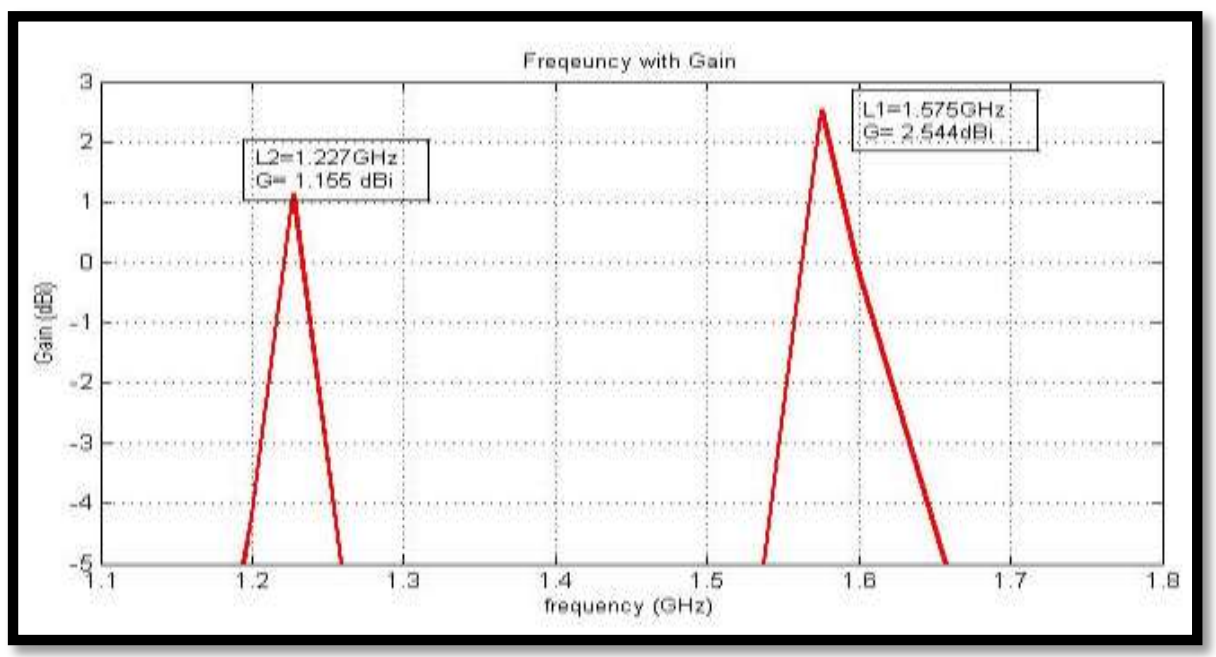

(a) 


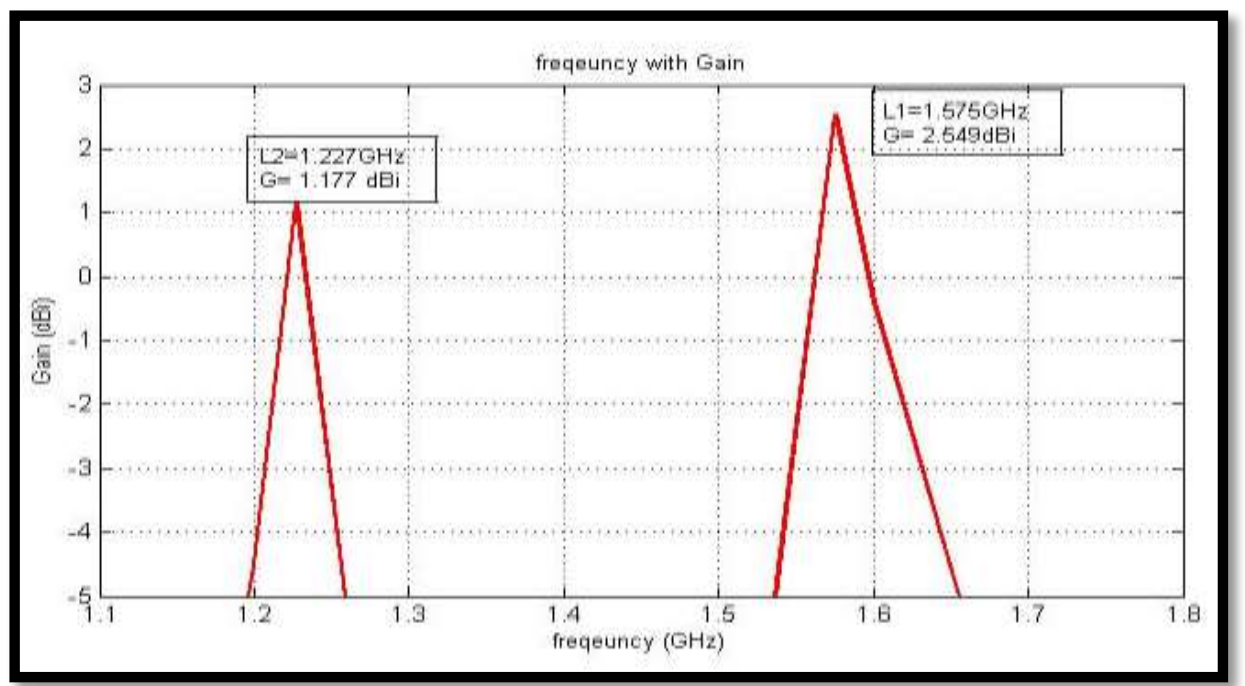

(b)

Figure (5) : The gain response of the proposed antenna.

(a) Gain for feed one. (b) Gain for feed two.

The radiation patterns for E-plane and $\mathrm{H}$-plane of the proposed antenna at frequencies $1.227 \mathrm{GHz}$ for $\mathrm{L} 2$ and $1.575 \mathrm{GHz}$ for $\mathrm{L} 1$ are shown at Figure (6). Figure (6 a) represent Eplane and $\mathrm{H}$-plane for feed one and Figure $(6 \mathrm{~b})$ represent E-plane and H-plane for feed two. The radiation patterns of the antenna are broadside unidirectional which is approximately the same with the radiation pattern of ideal GPS antenna .
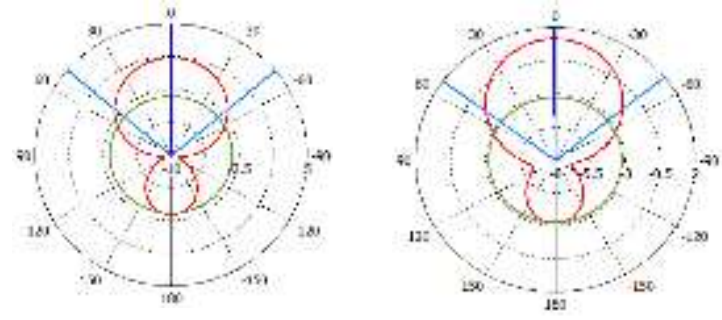

$\mathrm{H}$-plane phi=90 $1.227 \mathrm{GHz} \quad$ E-plane phi=0 $\quad 1.227 \mathrm{GHz}$

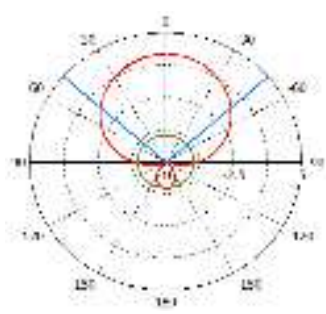

H-plane phi=90 $1.575 \mathrm{GHz}$

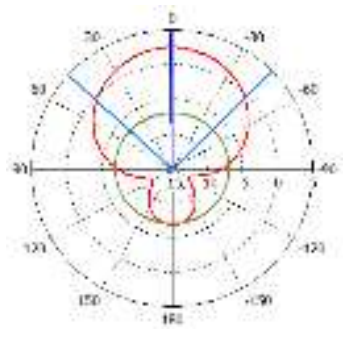

E-plane phi=0 $1.575 \mathrm{GHz}$

(a)

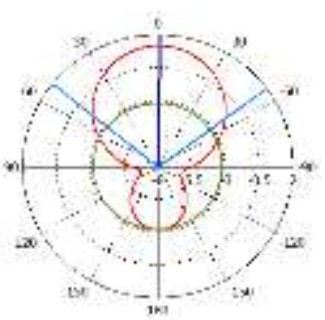

$\mathrm{H}$-plane phi=90 $1.227 \mathrm{GHz}$

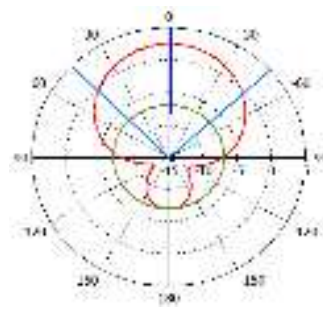

$\mathrm{H}$-plane phi=90 $1.575 \mathrm{GHz}$

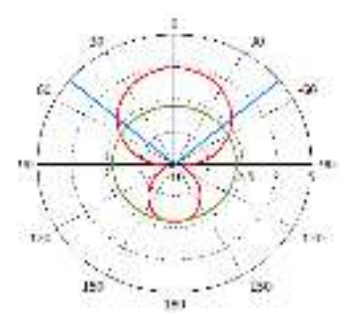

E-plane phi $=0 \quad 1.227 \mathrm{GHz}$

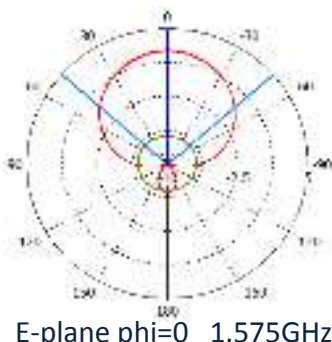

(b)

Figure (6): (a) The radiation pattern of the proposed antenna for feed one.

(b) The radiation pattern of the proposed antenna for feed two. 
The corresponding performance of the proposed antenna is depicted in Figure 7 and Figure 8. Where Figure 7 represents the VSWR and figure 8 represents Axial Ratio (AR) .For the CP microstrip antenna, the most attractive characteristic is axial ratio. For investigation the polarization characteristics of the GPS antenna, the axial-ratio was simulated over the whole L1 and L2 bands.

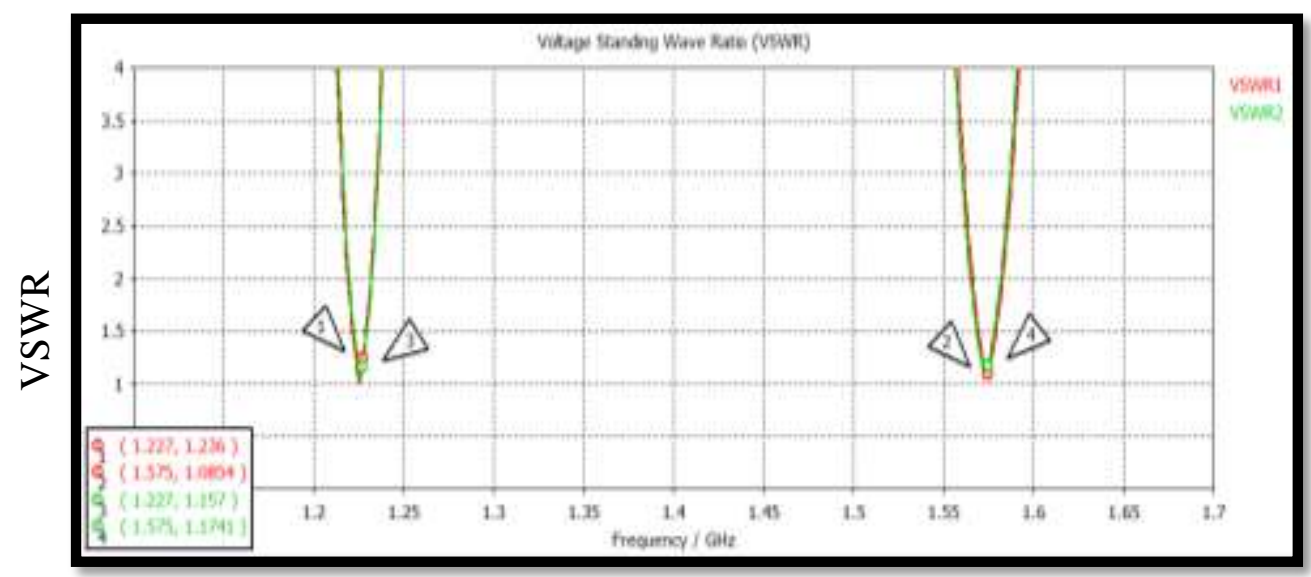

Figure (7) : VSWR of the proposed antenna.

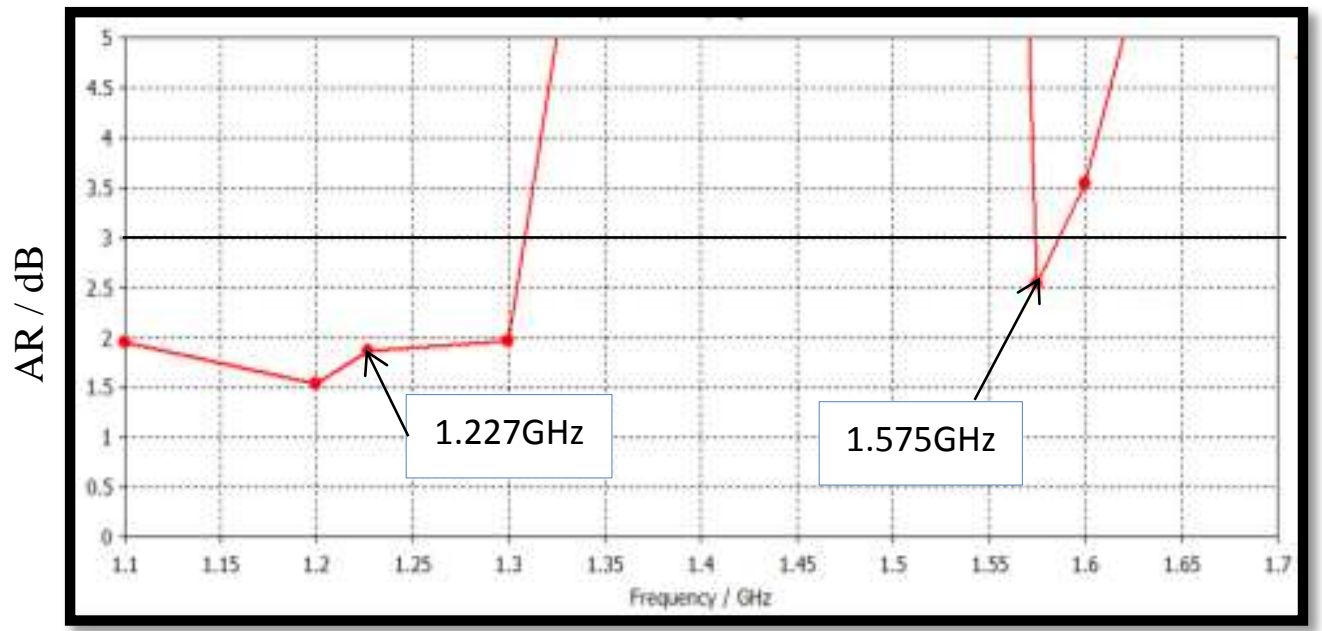

Figure (8): AR of the proposed antenna.

Table (1) shows a comparison between our results with results obtained from papers [9], [11],[12].

Table (1) shows a comparison between the results

\begin{tabular}{|c|c|c|c|c|c|c|c|c|}
\hline \multirow{2}{*}{\multicolumn{2}{|c|}{ papers }} & \multirow{2}{*}{$\begin{array}{c}\text { Over all } \\
\text { dimensions } \\
\left(\mathrm{m} * \mathrm{~m}^{2}\right)\end{array}$} & \multicolumn{2}{|c|}{ Return loss / S11 (dB) } & \multicolumn{2}{|c|}{ Axial Ratio / AR(dB) } & \multicolumn{2}{|c|}{ Gain (dBi) } \\
\hline & & & $1.575 \mathrm{GHz}$ & $1.227 \mathrm{GHz}$ & $1.575 \mathrm{GHz}$ & $1.227 \mathrm{GHz}$ & $1.575 \mathrm{GHz}$ & $1.227 \mathrm{GHz}$ \\
\hline \multirow[t]{2}{*}{$\begin{array}{c}\text { My } \\
\text { paper }\end{array}$} & $\begin{array}{c}\text { Feed } \\
\text { one }\end{array}$ & $70 * 70$ & -27.865 & -49.302 & 2.53 & 1.86 & 2.544 & 1.155 \\
\hline & $\begin{array}{l}\text { Feed } \\
\text { two }\end{array}$ & & -26.894 & -33.404 & 2.53 & 1.86 & 2.549 & 1.177 \\
\hline \multicolumn{2}{|c|}{ Paper [9] } & $130 * 130$ & 26.4 & -35.9 & 2.858 & 2.283 & 6.87 & 7.27 \\
\hline \multirow{2}{*}{\multicolumn{2}{|c|}{ Paper [11] }} & $140 * 140$ & -12.3 & -19.2 & 1.1 & 0.5 & 7.5 & 5.1 \\
\hline Paper [12] & & $100 * 100$ & -18.07 & -15.59 & |---------י & 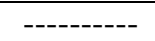 & 4.29 & 3.34 \\
\hline
\end{tabular}




\section{5- Conclusion}

In this paper, a new double feed compact dual-band microstrip patch antenna covering GPS operating frequencies at L1 $(1.575 \mathrm{GHz})$ and L2 $(1.227 \mathrm{GHz})$ has been demonstrated. The two layers of the proposed antenna use the same substrate material. The antenna shows good CP radiation characteristics at the two GPS operating frequencies. Two slots shaped $(+)$ are added in the upper patch, and four (I) shaped in the lower patch. An enhancement in return loss and gain are obtain due to adding slots.

At the same time this design method can be applied to other dual-band and multi-frequency antenna design. Furthermore, the antenna has a hemispherical radiation pattern with a good average gain throughout the operating bandwidth. This makes the proposed antenna design suitable for use in the GPS L1, L2 applications.

\section{6- References :}

[1]. D.M. Pozar and S.M. Duffy, "A dual-band circularly polarized aperture-coupled stacked microstrip antenna for global positioning satellite, " IEEE Trans Antennas Propagat. Vol. 45, pp. 1618-1625, 1997.

[2]. C. M. Su and K. L. Wong, "Adual-band GPS microstrip antenna, " Microwave Opt. Tech. Lett., vol. 33, pp. 238-240, 2002.

[3]. X.F. Peng, S.S. Zhong, S.Q. Xu, and Q. Wu, "Compact dual-band GPS microstrip antenna," Microwave Opt. Tech. Lett., vol. 44, pp. 58-61, 2005.

[4]. N. Padros, J.I. Ortigosa, J. Baker, M.F. Iskander, and B. Thornberg, "Comparative study of high-performance GPS receiving antenna designs, " IEEE Trans Antennas Propagat. Vol. 45, pp. 698-706, 1997.

[5] OH, J. OH, HONG, and Y. P, YOOK, "Dual circularly polarized stacked patch antenna for GPS/SDMB, " In IEEE International Symposium on Antennas and Propagation Society. San Diego (USA), p. 1-4, July 2008.

[6] KIM, SON, and J. M. YANG, "Design and implementation of dual band circular polarization square patch antenna," In Proc. Asia-Pacific Microwave Conf. (APMC 2005), Suzhou (China), p. 1-4, Dec. 2005.

[7] L. Changlu , "Antenna Measurement Techniques, " University of Electronics Science Technology of China Press. 1987.

[8] L. Xueguan, and G. Huiping , "Microwave Technology and Antennas, "Xidian University Press. 2006.

[9] U. U. Hussine, M. T. Islam, and N. Misran, "A New I Slotted Compact Microstrip Antenna for L1 \& L2 Bands," IEEE International Conference on Space Science and Communication (IconSpace), vol. 2, pp. 286-290, 12-13 July 2011.

[10] L. Boccia, G. Amendola, and G. D. Massa , "A high-performance dual frequency microstrip antenna for global position system, " IEEE Antennas and Propagation Society International Symposium, vol. 4, pp. 66- 69, 2001.

[11] X. Sun, Z. Zhang, and Z. Feng, "Dual-Band Circularly Polarized Stacked Annular-Ring Patch Antenna for GPS Application," IEEE ANTENNAS AND WIRELESS PROPAG AT ION LETTERS, VOL. 10, pp. 49-52, September 2011.

[12] U. U. Hussine, M. T. Islam, and N. Misran, “A Compact Dual-Band Gps Microstrip Antenna," Advances in Natural and Applied Sciences journal, vol. 6, pp. 1214-1218, 2012.

The work was carried out at the college of Engineering. University of Mosul 